\title{
Atenção à Saúde da População LGBT numa capital nordestina
}

\author{
Attention to health of the LGBT population in a northeastern capital
}

Atención de la salud para la población LGBT en una capital del noreste

Tereza Natália Bezerra de Lima ${ }^{1 *}$, Maria Eduarda Lima de Carvalho ${ }^{1}$ Joelma Laurentino Martins de Souza ${ }^{1}$, Ilka Jenifer Menezes Taurino², Camila Rodrigues de Freitas ${ }^{2}$, Andréia Patrícia Terenci ${ }^{2}$, Helena Maria da Silva Oliveira ${ }^{3}$, Jéssica Lucia dos Santos ${ }^{4}$, Débora Rafaela Amorim Ferreira ${ }^{5}$, Mayra Salgado de Lucena ${ }^{6}$.

\section{RESUMO}

Objetivo: Identificar, a partir da compreensão de gestores e profissionais de saúde, as dificuldades e desafios, potencialidades e facilidades encontradas na Atenção à Saúde Integral de Lésbicas, Gays, Bissexuais, Travestis e Transexuais, no município do Recife. Métodos: É uma pesquisa de natureza exploratória, com metodologia qualitativa, realizada com entrevistas semiestruturadas, colhidas de gestores e profissionais de quatro estabelecimentos de saúde que direcionam ações voltadas para população LGBT, tanto a nível de gestão, quanto assistencial. As entrevistas foram realizadas de maneira individual, gravadas, e posteriormente transcritas. A análise dos dados coletados foi feita através da Análise de Discurso, da qual emergiu duas categorias temáticas: conhecimento sobre a Política de Saúde Integral a População LGBT e o entendimento sobre a Atenção à Saúde Integral a população LGBT. Resultados: A análise dos dados coletados foi feita através da Análise de Discurso, da qual emergiu duas categorias temáticas: conhecimento sobre a Política de Saúde Integral a População LGBT e o entendimento sobre a Atenção à Saúde Integral a população LGBT. Conclusão: Foi possível conhecer a percepção dos entrevistados, tornando visível as necessidades de direcionar ações mais amplas a população LGBT, preenchendo algumas lacunas na construção da Atenção Integral à Saúde, desde acolhimento, acesso aos serviços de saúde, a qualidade do atendimento oferecida, tornando o estudo com profissionais de saúde e gestores praticamente pioneiro na produção cientifica brasileira.

Descritores: Minorias Sexuais, Políticas Públicas de Saúde, Atenção à Saúde.

\begin{abstract}
Objective: Identify, based on the comprehension of healthcare managers and professionals, obstacles and challenges, potential and facilities found in the Attention to Integral Health of Lesbians, Gays, Bisexuals, Transvestites, Transsexuals in the city of Recife. Methods: This research is of exploratory nature with qualitative methodology having half-structured interviews with managers and professionals of four health institutes that promote actions directed to LGBT population. Results: Interviews were accomplished, recorded and transcribed. The data analysis was made using the Speech Analysis method from which two categories came up: managers and professionals knowledge about LGBT Integral Health Policy as well as their understanding of Attention to Integral Health. Conclusion: It was possible to understand their perception, making it visible to the need of direct actions to this part of population, making this research unique to Brazilian scientific production.
\end{abstract}

Key words: Sexual Minorities, Public Health Policy, Health Care.

\footnotetext{
1 Universidade de Pernambuco (UPE), Recife-PE. *E-mail: terezanatalia12@gmail.com

${ }^{2}$ Centro de Formação e Aperfeiçoamento Profissional (CEFAPP), Recife-PE.

${ }^{3}$ Faculdade São Miguel (UNISÃOMIGUEL), Recife-PE.

${ }^{4}$ Faculdade dos Guararapes (FG), Jaboatão dos Guararapes-PE.

${ }^{5}$ Faculdades Integradas da Vitória de Santo Antão (FAINTVISA), Vitória de Santo Antão-PE.

${ }^{6}$ Centro Universitário do Vale do Ipojuca (UNIFAVIP/Wyden), Caruaru-PE.
} 


\section{RESUMEN}

Objetivo: Identificar la comprensión de los gerentes y profesionales de la salud, las dificultades y desafíos, las potencialidades y las instalaciones que se encuentran en la atención integral de la salud de las personas lesbianas, gays, bisexuales, travestis y transgénero, en la ciudad de Recife. Métodos: Esta es una investigación exploratoria, con metodología cualitativa, realizada con entrevistas semiestructuradas, recopiladas de gerentes y profesionales de cuatro establecimientos de salud que dirigen acciones dirigidas a la población LGBT, tanto a nivel gerencial como de atención. Las entrevistas se realizaron individualmente, se grabaron y luego se transcribieron. El análisis de los datos recopilados se realizó a través del Análisis del Discurso, del cual surgieron dos categorías temáticas: el conocimiento sobre la Política de Salud Integral para la población LGBT y la comprensión sobre la Atención de Salud Integral para la población LGBT. Resultados: El análisis de los datos recopilados se realizó a través del Análisis del Discurso, del cual surgieron dos categorías temáticas: el conocimiento sobre la Política de Salud Integral para la población LGBT y la comprensión sobre la Atención Integral de Salud para la población LGBT. Conclusión: Fue posible conocer la percepción de los encuestados, haciendo visible la necesidad de dirigir acciones más amplias a la población LGBT, llenando algunas brechas en la construcción de la Atención Integral de Salud, desde la recepción, el acceso a los servicios de salud, la calidad de la atención ofrecida, haciendo estudio con profesionales y gerentes de salud prácticamente pionero en la producción científica brasileña.

Descriptores: Minorías Sexuales, Política de Salud Pública, Atención de la Salud.

\section{INTRODUÇÃO}

O direito à saúde, internacionalmente, foi reconhecido através da aprovação da Declaração Universal dos Direitos Humanos em 1948, pela Organização das Nações Unidas (ONU). No Brasil, o direito à saúde veio, primeiramente, para trabalhadores com vínculo formal, que contribuíam para a Previdência Social, privando a maioria da população ao acesso as ações de saúde, restando à assistência prestada por entidades filantrópicas (CHIANCA KSV, 2011).

A conquista desse direito veio com a luta do Movimento da Reforma Sanitária, garantida pela Constituição Federal de 1988, na qual a saúde é entendida de maneira ampliada, através do tripé Saúde, Previdência Social e a Assistência Social. A concepção da saúde passou a ser direito de todos e dever do Estado, garantido por políticas sociais e econômicas que visem à redução de doenças e de outros agravos assim como ao acesso universal e igualitário às ações e serviços para a sua promoção, proteção e recuperação (PEREIRA EO, 2015; CARDOSO MR e FERRO LF, 2012).

Mesmo com a legislação presente garantindo o direito ao acesso à saúde, existem parcelas da população que demandam atenção especial no que diz respeito ao atendimento em serviços de saúde, por várias questões culturais e sociais, que são as mulheres, os idosos e a população de Lésbicas, Gays, Bissexuais, Travestis e Transexuais (LGBT) (SOUZA MBCA e HELAL DH, 2015).

Na óptica de Paula CEA, et al. (2017), retrata que a vulnerabilidade caracteriza um grupo em posição de subordinação e inferioridade, e esse fato os transformava em seres passíveis de exclusão e maus tratos, como estigmatização e discriminação, atualmente ainda se promove a ideia de que são grupos protagonistas na disseminação da doença (AYRES JRCM, 2005; PAULA CEA, et al., 2017).

Por ser uma população historicamente vinculada a vários estigmas, preconceitos e perseguições por sua orientação sexual e identidade de gênero, assim como sua associação inicial com a epidemia AIDS, desencadeiam processos de sofrimento, adoecimento e morte prematura, afastando-se dos ambientes de cuidados em saúde pelo fato de seus membros reproduzirem discursos homofóbicos, e implicando esses fatores na determinação social da saúde (PEREIRA EO, 2015; GUIMARÃES RCP, et al., 2017; PEREIRA EO, et al., 2017).

O reconhecimento da complexidade da Saúde da População LGBT, no Brasil, emergiu no final da década de 1980, com a inserção de ações de saúde direcionadas às demandas para esse grupo populacional, tendo como foco o enfrentamento da epidemia do Vírus da Imunodeficiência Humana/ Síndrome da 
Imunodeficiência Adquirida (HIV/AIDS), no período que ficou conhecido como "câncer gay" ou a "peste gay" devido a maior incidência e prevalência nessa parcela da população (PEREIRA EO, 2015; ROLIM AGF, et al., 2016) . Assim, se deu o início da parceria do Ministério da Saúde e dos movimentos sociais vinculados no primeiro momento aos grupos de defesa aos direitos de grupos gays, visando o combate de epidemia (CARDOSO MR e FERRO LF, 2012; BRASIL, 2010).

Como resultado desses esforços, houve uma série de mudanças no corpo social que levou o Ministério da Saúde a ir além do combate à AIDS, tornando mais evidente as questões de saúde de lésbicas, gays, bissexuais, travestis e transexuais, reconhecendo a necessidade da construção de uma política de saúde integral a essa população. Em 2010, o Ministério da Saúde institui pela Portaria $n^{\circ} 2.836$, a Política Nacional de Saúde Integral da população LGBT. O processo de construção dessa política representou um novo momento, trazendo uma abordagem de caráter transversal, envolvendo todas as áreas de saúde do Ministério da Saúde interligadas desde a produção de conhecimento, participação social, promoção, atenção e cuidado em saúde (SOUZA MBCA e HELAL DH, 2015).

A Política reafirma o compromisso do Sistema Único de Saúde (SUS), seguindo seus princípios de universalidade, integralidade, participação da comunidade, e reconhecendo as desigualdades existentes na saúde criando respostas para minimizá-las (GUIMARÃES RCP, et al., 2017). É uma iniciativa para a construção de mais equidade no SUS (FACCHINI R e BARBOSA RM, 2006). Contendo vários objetivos: ampliar o acesso da população LGBT aos serviços de saúde; atender em especial às suas necessidades e demandas em saúde; qualificar a rede de serviços; luta pela eliminação do preconceito, discriminação, violência e exclusão nos serviços de saúde; oferecer atenção e cuidado à saúde de adolescentes e idosos na população LGBT; reduzir danos à saúde no uso excessivo de hormônios e medicamentos e garantir o uso do nome social de travestis e transexuais (BRASIL, 2010; GUIMARÃES RCP, et al., 2017).

Para Mello L, et al. (2012), os serviços de saúde fundados nos princípios de universalidade, integralidade e equidade, não devem cogitar da orientação sexual e identidade de gênero como atributos identitários ou marcadores sociais únicos, mas articulados de diversas maneiras (PEREIRA EO, 2015). Dessa forma, a Atenção à Saúde na população LGBT prestada por profissionais de saúde, requer reflexões desde a importância da organização de práticas em saúde, do acesso aos serviços de saúde e das suas necessidades de saúde; focalizando as ações e políticas como ferramentas sociais para o combate a homofobia e violações dos direitos humanos fundamentais (BRASIL, 2010).

Nesta perspectiva, de acordo com Guimarães RCP, et al. (2017), menos de 10\% das pessoas LGBT do planeta tem acesso à prevenção e ao atendimento, no que se refere à pessoa trans. O Dossiê Saúde das Mulheres Lésbicas promoções da equidade e da integralidade (2006) aponta que as mulheres lésbicas, ou bissexuais não revelam sua orientação sexual nas consultas. Dentre as que revelam $28 \%$ considera que 0 atendimento é realizado de forma mais apressada e 17\% alega a ausência de solicitação de exames (FACCHINI R e BARBOSA RM, 2006).

Diante da complexidade da situação da população LGBT, esse estudo pretende enfatizar que as necessidades em saúde dessa população sejam atendidas de maneira qualificada, respeitando não somente as características intrínsecas dessa população, mas refletindo sobre as consequências das representações e significados que recaem sobre suas práticas sexuais e modos de vida (LIONÇO T, 2008). É preciso, portanto, compreender as lacunas e possibilidades da abordagem oferecida pelos profissionais envolvidos na assistência e gestão da saúde, para a construção de um atendimento adequado à população LGBT nos serviços, garantindo assim, o pleno exercício da cidadania dessa população, bem como tornar visível as ideologias e o real cenário em relação à atenção à sua saúde.

Considerando o exposto, esse texto é fruto de um projeto de conclusão do curso de Residência Multiprofissional em Saúde Coletiva da Universidade de Pernambuco (UPE), o qual tem como objetivo, identificar, a partir do entendimento dos gestores e profissionais de saúde, as dificuldades e desafios, potencialidades e facilidades encontradas na Atenção à Saúde Integral de Lésbicas, Gays, Bissexuais, Travestis e Transexuais, em um município do Recife. 


\section{MÉTODOS}

Este artigo apresenta o resultado de uma pesquisa de campo, de natureza exploratória e abordagem qualitativa, aprovado pelo Comitê de Ética em Pesquisa do Hospital Universitário Oswaldo Cruz (HUOC) da Universidade de Pernambuco, sob o no 2.461 .712 e recebido anuência institucional da Secretaria Municipal de Saúde do Recife. A aplicação dos procedimentos de investigação seguiu e respeitou os valores éticos da Resolução 196/96 do Conselho Nacional de Saúde (CNS).

O cenário consiste na capital pernambucana, a qual se situa no litoral nordestino, apresentando um território de 218,4 km², com população de 1.537 .704 pessoas, e densidade demográfica de $7.039,64 \mathrm{hab} / \mathrm{km}^{2}$ (IBGE, 2017).

Foram selecionados estabelecimentos de saúde que direcionam ações voltadas para população LGBT, tanto ao nível de gestão, quanto assistencial. Lembrando que esse recorte se deve ao fato de que os mesmos compartilham esforços diretamente para a atenção à saúde da população LGBT, e estão distribuídos geograficamente no município em três distritos sanitários distintos (I, II e IV) (RECIFE, 2014).

Foram escolhidos propositalmente quatro estabelecimentos de saúde que consistem: no nível de gestão, a coordenação da Política de Saúde Integral a População LGBT do Recife; no nível assistencial, o Centro Municipal de Referência em Cidadania LGBT do Recife; ambulatório LGBT-Patrícia Gomes na policlínica Lessa de Andrade; e o ambulatório especializado para mulheres Lésbicas, Bissexuais e Transexuais - LBT situado no Hospital da Mulher do Recife.

Para coleta de dados, foram realizadas entrevistas individuais semiestruturadas, que foram gravadas e posteriormente transcritas. Um roteiro foi previamente elaborado, sendo guia para a pesquisadora nas entrevistas. Dessa forma, as entrevistas visaram identificar, nas diversas falas, os significados dos profissionais de diversas categorias no que diz respeito à atenção à saúde e suas potencialidades e dificuldades quando dirigidas para a população LGBT. Além disso, possibilitaram identificar a organização do processo de trabalho das unidades (MINAYO MCS, 1993).

Os sujeitos da pesquisa foram recrutados pelos seguintes critérios de inclusão: ter nível superior, ser profissional de saúde vinculado a Atenção à Saúde Integral à população LGBT, ser profissional dos estabelecimentos de saúde selecionados, ser do quadro efetivo ou contratados pela Prefeitura Municipal do Recife e confirmar a participação no estudo, a partir da assinatura do Termo de Consentimento Livre e Esclarecido (TCLE).

Para a coleta de dados, foi utilizada a técnica Snowball (bola de neve), que consiste em amostra não probabilística, em que cada participante indica outras pessoas com as características desejadas, quer elas sejam ou não de seu próprio meio social, levando a incremente da amostragem, até que se atinja o ponto de saturação, quando a coleta será suspensa porque novas entrevistas nada acrescentarão à pesquisa (VINUTO $\mathrm{J}$, 2014). Foram entrevistados sete profissionais, dos quais três encontravam-se em cargo de gestão, e quatro como profissionais assistenciais.

Após a transcrição na integra das entrevistas, chegou-se ao momento da análise. Inicialmente, desde o projeto, pretendia-se o uso da técnica de Análise de Conteúdo, seguindo a orientação teórica de Laurence Bardin (1977).

No entanto, com o progredir das leituras, percebeu-se que esse tipo de material deveria ser tratado por Análise de Discurso (AD), visto que a densidade dos depoimentos requeria uma interpretação do sentido para além do falado, conforme os três princípios abordados por Orlandi PE, (2015), na qual, descreve a importância da língua como uma ordem única e própria, no primeiro ponto que a língua é capaz de reintroduzir a noção de sujeito e na de situação análise da linguagem; no segundo principio mostra que a história é afetada pelo simbólico, e pelos fatos reclamam sentidos; e por último ponto, que o sujeito de linguagem apresenta-se de modo descentralizado, sendo afetado pelo real da língua e como também pela história, não tendo o controle sobre o modo como elas o afetam. Desta forma, o sujeito discursivo funcionará pelo inconsciente e pela ideologia. 
Assim, AD não é uma metodologia, mas sim uma disciplina de interpretação, na perspectiva da área de saúde, que vem como um meio de inclusão da linguagem em um sistema abstrato, no qual o indivíduo se expressa através de palavras, resultando em sentidos que afirmem sua percepção sobre a determinação social do processo saúde-doença (MINAYO MCS, 1993; MACEDO LC, et al., 2008).

Todo o material analisado foi organizado em categorias temáticas. Para Minayo MCS (1993), esse tipo de procedimento pode ser utilizado em qualquer tipo de análise de pesquisa qualitativa, trabalhando com categorias significativas agrupando elementos, ideias ou expressões acerca de um conceito, estabelecendo classificações.

Devem descrever de forma clara e sem prolixidade as fontes de dados, a população estudada, a amostragem, os critérios de seleção, procedimentos analíticos e questões éticas relacionadas à aprovação do estudo por comitê de ética em pesquisa (pesquisa com seres humanos e animais) ou autorização institucional (levantamento de dados onde não há pesquisa direta com seres humanos ou animais).

\section{RESULTADOS E DISCUSSÕES}

Foram entrevistados sete profissionais, dos quais três encontravam-se em cargo de gestão, e quatro profissionais assistenciais. O total de entrevistados constituíram dois grupos no nível de gestão: um médico, um assistente social e um enfermeiro; e no nível assistencial: um psicólogo, um médico, dois assistentes sociais. Para organizar de maneira mais didática, e manter em sigilo a identidade dos participantes, estes receberam nomes fictícios. Além disso, foi elaborado o Quadro I com algumas informações sociodemográficas dos entrevistados, de forma a caracterizar esses informantes, personificando-os para os leitores (Quadro 1).

Quadro 1 - Características sociodemográficas dos informantes.

\begin{tabular}{|c|c|c|c|c|c|c|}
\hline $\mathbf{N}^{\circ}$ & Entrevistado & Idade & $\begin{array}{c}\text { Formação } \\
\text { profissional }\end{array}$ & $\begin{array}{c}\text { Cargo no } \\
\text { momento da } \\
\text { pesquisa }\end{array}$ & $\begin{array}{c}\text { Militante de } \\
\text { movimento } \\
\text { social }\end{array}$ & Vínculo empregatício \\
\hline 1. & Luz & 33 anos & Serviço social & Coordenador * & Sim & Efetivo \\
\hline 2. & Flor & 41 anos & Serviço social & $\begin{array}{l}\text { Assistente } \\
\text { social }\end{array}$ & Não & CLT \\
\hline 3. & Arco-íris & 37 anos & Enfermagem & $\underset{* *}{\text { Coordenador }}$ & Sim & CLT \\
\hline 4. & Borboleta & 55 anos & Serviço social & $\begin{array}{l}\text { Assistente } \\
\text { social }\end{array}$ & Não & CLT \\
\hline 5. & Abelha & 46 anos & Psicologia & Psicologista & Sim & CLT \\
\hline 6. & Coruja & 41 anos & Medicina & $\underset{* \star *}{\text { Coordenador }}$ & Não & CLT \\
\hline 7. & Nuvem & 35 anos & Medicina & Clínico-geral & Sim & Efetivo \\
\hline
\end{tabular}

Legenda: * Coordenação da Política Municipal de Atenção à Saúde da População LGBT. * Coordenação do ambulatório LGBT - Patrícia Gomes. ${ }^{* * *}$ Coordenação do ambulatório LBT no Hospital da Mulher

Fonte: Lima TNB, Carvalho MEL, Souza JLM, et al., 2017.

No que diz respeito ao perfil dos entrevistados, com média de idade de 41 anos, idade mínima de 33 e máxima de 55 anos. As maiorias dos entrevistados cumpriam carga de 40 horas semanais, possuíam mais de um ano de atuação nos estabelecimentos de saúde direcionados à atenção à saúde LGBT. Em relação à formação especifica na saúde LGBT, possuíam, em média, uma formação dada pelo nível federal, municipal e cursos a distância. No que diz respeito ao regime de contratação, há apenas dois em regime efetivo, e os demais em regime de contrato CLT (Consolidação das Leis do Trabalho).

Dos sete entrevistados, quatro eram membros do movimento de militância na saúde da população em estudo, os quais reafirmam a participação da comunidade na construção de políticas públicas, assim como aconteceu na formulação da Política Estadual da Atenção Integral à população LGBT, que veio de forma articulada entre os órgãos governamentais e a sociedade através dos movimentos sociais, repetindo 0 panorama nacional (PERNAMBUCO, 2015). 
$\mathrm{Na}$ análise dos dados não se fez a partir da distribuição de profissionais por nível de atribuição na unidade de saúde, mas a partir das temáticas mencionadas nas falas, que permitiram a categorização. $\mathrm{Na}$ qual as ideias centrais apresentadas nas entrevistas foram sistematizadas nas seguintes categorias temáticas: conhecimento dos gestores e profissionais de saúde sobre a Política de Saúde Integral a População LGBT e o entendimento dos profissionais e gestores sobre a Atenção à Saúde Integral a população LGBT.

Categoria 1 - Conhecimento dos gestores e profissionais de saúde sobre a Política de Saúde Integral a População LGBT

A produção científica carece de trabalhos que abordem a política de saúde da população LGBT como temática central, na perspectiva dos profissionais e gestores em saúde. Na revisão integrativa de Prado EAJ e Sousa MF (2017), mostrou-se que a maiorias dos trabalhos realizados sobre a temática LGBT tinham como pesquisados os próprios usuários do sistema de saúde. Os debates incluíam discriminação a que os usuários estavam submetidos no sistema de saúde; processo transexualizador no SUS e atenção à saúde da população transexual. Repetindo essa tendência, essa categoria vai abordar as políticas de saúde a essa população, mas com o foco do conhecimento dos gestores e profissionais sobre a aplicabilidade, entendimento e importância no seu processo de trabalho.

Outro ponto a ser lembrado, é que o cenário pernambucano é referência nacional, na atenção à saúde da população LGBT, apresentando politicas instituídas e inseridas na rede de atenção à saúde, tanto em nível estadual como também no município do Recife.

Quando aos profissionais entrevistados foi perguntado se conheciam as políticas de saúde tanto no nível federal, estadual e municipal, a maioria respondeu que conhece mais a política municipal do que a estadual e nacional. Nenhum deles revelou desconhecimento de qualquer uma as três políticas citadas. No entanto, aparentemente há uma certa fragmentação desse conhecimento:

"Os direitos sociais e a questão da saúde como todo, principalmente no nosso programa LBT na questão da prevenção, a grande maioria não faz, não se cuida e nem conhece as próprias políticas". (Borboleta)

"É as prioridades, é o respeito, é a principal luta que eu vejo é muito pela questão não discriminação, acho que isso vem sendo apoiado em todas as políticas". (Flor)

"Eu vejo que existe uma.... Que veio para sanar a necessidade de um segmento que a tanto tempo é, não teve acesso por alguns tipos de preconceitos, discriminações ou falta de esclarecimento". (Arco-íris)

Primeiramente, é preciso compreender que a política é um resultado de vários interesses e representações de diversos fatores sociais, e que na maioria das vezes lutam por ideais contraditórios24. Dessa maneira, é possível observar que as falas apresentam como foco central as palavras-chave: direitos sociais, luta, preconceito e discriminação, que são as ideias mais relevantes nas discussões sobre a população LGBT (PRADO EAJ e SOUSA MF, 2017). Dessa forma, por serem profissionais de saúde, evidenciam esse cenário complexo vivenciado no seu cotidiano de trabalho.

"É eu saber o que realmente o quanto eu vou exigir! O que eu posso exigir! ..., hoje ela me serve como uma ferramenta de trabalho, de dizer que pode fazer isso dessa maneira que a política coloca isso para a gente, hoje é mais como ferramenta e antes como formação" (Nuvem).

Outros depoimentos evidenciam a importância do conhecimento sobre as políticas de saúde e seu papel na transformação da realidade social. Segundo Lionço T (2008), mesmo a política de saúde sendo recentemente formulada no Brasil, ela já se apresenta como sinalização de desafios a serem superados para o avanço dos direitos sexuais no contexto da saúde pública. Isto aparece claramente no depoimento abaixo:

"A Política de Atenção à Saúde da População LGBT ela tem como marco maior fazer justamente que outras políticas, que outros serviços, e segmentos da saúde 
enxergue a população LGBT como uma população que necessita de cuidados, ou seja, então eu considero uma política de desbravamento mesmo, a gente vai desbravando territórios, consolidando territórios a qual há muito tempo não se enxergava essa população, enquanto população de cuidado e aí. E também outra coisa importante é o aspecto de resistência né, é uma política que sofre ataque diariamente e aí, ela precisa consolidar e resistir nos avanços que são muito poucos que foram conquistados" (Luz).

As políticas e os programas direcionados à população LGBT surgiram da necessidade de uma proposta de mudança e da carência de políticas públicas, na qual Laurentino ACN (2015) ressalta a baixa procura por atendimento nos postos e unidades de saúde, aumentando a incidência e prevalência de ocorrência dos agravos, relacionados a fatores ambientais, sanitários, econômicos e/ou sociais.

Em relação aos recursos disponíveis para implementação da política no município, uma das falas evidencia a limitação de recursos tanto no nível humano, material financeiro, demostrando o conhecimento em relação a esses recursos.

"É a primeira é a falta de recurso... que limita muito a atuação da gente enquanto política né, porque sem recurso você fica atado a trabalha somente alguns aspectos de promoção, prevenção e cuidado. Mais, é isso" (Luz).

Outro desdobramento exposto nas ideias dos entrevistados foi à concepção de alguns objetivos apresentados nas políticas direcionadas a essa população, que são seguintes elementos: ações de promoção/prevenção/reabilitação; acesso a atenção da população LGBT na Atenção Básica; e acesso na Atenção especializada de Média e Alta complexidade. Esses elementos ampliam o atendimento e os serviços disponibilizados no reconhecimento da necessidade de uma abordagem integral independente do nível de atenção à saúde em que é realizado (LAURENTINO ACN, 2015). Os três entrevistados abordam esses elementos de maneira distinta:

"O motivo de ação de promoção/prevenção é o nosso objetivo por estar na Atenção Básica, então a gente faz isso desde antes da porta, eu converso com os grupos que já estão ali esperando e fazer essa triagem, eu já explico o que é esse equipamento, eu já digo as demandas que possivelmente que essas pessoas podem tá vindo para ser atendidas aqui, para que ela faça também essa disseminação de informações para poder a gente ser mais visibilizados, para dizer que aqui é um direito nosso" (Arco-íris).

"Outra coisa é o acesso da população na atenção básica, a população LGBT vai logo aos serviços de média e alta complexidade de uma certa forma que são especialidades e que são urgências e emergências e por aí vai. " (Luz).

"Todas essas unidades, independe do nível de atenção vão tá capacitadas para poder ta atendendo essas pessoas e não ta tirando esses acessos, mas aqui faz isso quando a pessoa não tem acesso direto com as unidades próximas na sua casa, vem para o hospital né" (Coruja).

Observa-se que esses discursos apresentam várias concepções no que diz respeito ao acesso aos serviços em diferentes níveis de complexidade. Segundo Laurentino ACN (2015), ainda tem serviços que não favorecem o acesso às ações de saúde, desde gestores que não pensam na inclusão dessa população em suas ações, bem como os profissionais, o atendimento que não superam de seus próprios preconceitos. LGBT

Categoria 2 - Entendimento dos profissionais e gestores sobre a Atenção à Saúde Integral à população

O escritor e teólogo brasileiro, Leonardo Boff (2004), define que o "cuidar é mais que um ato; é uma atitude", surge somente quando a existência do outro tem importância para mim (BOOF L, 2004). Com esse 
pensamento, o cuidado para com a população LGBT deve ser construído mediante a superação de agravos decorrentes dos processos discriminatórios, respeitando suas necessidades específicas de saúde. Ao mesmo tempo, exige um conhecimento sobre conceitos de identidade de gênero e sexual, e do cuidado sobre os laços sociais e da inserção social da população LGBT (CARDOSO MR e FERRO LF, 2012; LIONÇO T, 2008). Isto requer reconhecer a complexidade envolvida nos preceitos heteronormativos que levam a tais práticas discriminatórias.

Nos estudos de Pereira EO et al., (2017) foi possível analisar que é "longo e difícil caminho para a superação do preconceito e da discriminação, que solicita de cada um e do coletivo, mudanças baseadas no respeito às diferenças". O informante Nuvem relata isto de forma explicita:

"Eu vejo a dificuldade deles chegarem, mas a gente tem o costume de jogar no outro, mas será que ele não vem porque eles não sabem do serviço? Ou será mesmo sabendo do serviço público não comparece? Já existe o ambulatório LBT inclusive para fazer que eles cheguem, então já foi aberto um espaço para eles, que na realidade deveria ser um espaço coletivo, como eu enxergo o LBT, o LGBT e essas siglas gigantes como sujeito não deveria existir nenhuma diferença, e quando eu chegar aqui em uma recepção dessas e chegar um determinado estereótipo, que vai chegar algo estereotipado! $E$ as pessoas não olharem estranho e não terem preconceito, eu acho que é uma reeducação da sociedade como um modo que tem que ser" (Nuvem).

Albuquerque EA et al., (2013) aponta que a necessidade de reformulações dos espaços de saúde para a inclusão da população LGBT depende das transformações no modo de pensar e agir dos profissionais, evidenciando a importância do acesso, do acolhimento e da humanização nos serviços de saúde.

Cardoso MR e Ferro LF (2012) descrevem que as questões culturais ligadas ao padrão heteronormativo influenciam, de modo subjetivo, o atendimento dos profissionais de saúde, o que os leva a assistir todos os usuários como se fossem heterossexuais, o que gera situações graves de discriminação e preconceito contra essa parcela da população.

"Eu acho que é ainda o preconceito deles mesmos em procurar os serviços sabe, medo e receio de procura os serviços e chega nesse serviço humanizado e a gente procura ser e ainda acha que tem preconceito, e tem na verdade, tem sim, talvez não aqui que é um espaço de referência, mas com certeza existe" (Flor).

Os estudos de Barbosa RM e Facchini R (2009) (ALBUQUERQUE EA, et al., 2013; BARBOSA RM e FACCHINI R, 2009) apontaram que essa população apresenta alguma resistência à procura dos serviços de saúde, que em suma, evidencia algum contexto discriminatório, pelo fato da organização do serviço ter a heterossexualidade como predominante, pela falta de qualificação ou até pelo preconceito dos profissionais de saúde para atender a essa demanda.

Pereira EO, et al., (2017) reforça que não são só as práticas discriminatórias que afastam o acesso a saúde da população LGBT, mas também a impropriedade da oferta de cuidados.

Esses mesmos autores identificam que a relação profissional/usuário era de suma importância na qualidade da assistência em saúde, mas em sua pesquisa evidenciou-se a fragilidade no processo de comunicação, perdendo assim, oportunidade para a promoção da saúde. No presente estudo, a palavra vínculo foi relacionada pelo menos pela metade dos entrevistados ao acolhimento e humanização, apresentando diversos sentidos atribuídos por eles (ALBUQUERQUE EA, et al., 2013; BARBOSA RM e FACCHINI R, 2009; PEREIRA EO, et al.,2017).

"Primeiramente manter logo um vínculo com a paciente, ela se senti bem à vontade e aí gente fala sobre o sigilo, sobre a entrevista social e aí a partir daqui quando se cria esse vínculo e ela fala sobre a historinha de vida dela e as necessidades básicas mesmo de saúde, de prevenção, de cuidado mesmo..." (Borboleta). 
"É importante você está no espaço onde você possa fala o que você quiser e identificar como você quer é, pessoas que entendem a causa e que torcendo por isso, aí a pessoa fica à vontade, a pessoa fala, fica leve."(Flor).

"Eu acredito que exatamente pela gente chegar perto desse paciente construir esse vínculo, vamos fala no serviço público aqui tem um serviço relativamente diferenciado porque assim, poucas unidades de saúde têm duas psicólogas $12 \mathrm{~h}$ e. Que estão aqui para escutar, então a pessoa ser escuta as vezes é um privilégio, e escuto muito, e se você não der continuidade esse trabalho não vai chegar a dissolver um sintoma, sem tudo isso, sem humanização a pessoa vai embora" (Abelha).

Desse modo, o profissional de saúde tem um papel fundamental na identificação dos fatores que possam interferir de alguma maneira no processo de saúde da população LGBT, e a escuta é um instrumento de trabalho, tornando qualificada e humanizada, fortalecendo a elaboração de práticas em saúde mais focadas nas necessidades dessa população (CARDOSO MR e FERRO LF, 2012).

Nos depoimentos dos profissionais, outra temática bem discutida foi a Educação na Atenção à Saúde na população LGBT. Parte dos profissionais mostra interesse na busca de qualificação direcionada a essa população, o que na maioria das vezes ocorre por iniciativa própria:

"Eu fiz através da internet, aquele do UNASUS e depois fiz uma assim que entrei no ambulatório. A última foi pela ordem dos advogados pela $O A B$, muito boa, sobre os direitos deles sabe. " (Borboleta).

"Eu fiz um estágio no hospital das clinicas no ambulatório de lá e fiz o curso do UNASUS." (Coruja).

Além disso, alguns informantes demostraram inquietudes em relação à ausência da temática nas próprias formações profissionais e/ou a dificuldade do acesso à informação sobre as demandas específicas da população LGBT durante a formação.

“...até mesmo na minha carreira profissional não tinha atendido tantas demandas diferenciadas como estou atendendo agora, como enfermeiro nunca tinha atendido dessa forma e que tem algumas coisas que são novas ainda para mim, mas é aquele negócio, parece que já vejo isso a mil anos, é muita naturalidade, e a gente como é muito militante também tem a questão por própria identidade só sai daqui quando eu revolver problema" (Arco-íris).

"As faculdades não ensinam como a gente vai mexer com isso e aquilo e como sou professor de faculdade, digo muito aos alunos: que eles parem de ter essa ideia de quem é mulher e quem é homem, e de esposa e marido, mas quem é a pessoa com que você está! A gente tem que respeitar a orientação e a forma como a pessoa se encontra e se entende naquele momento, aí eu acho que essa história de capacitar o profissional, perdão mas de sim ensinar que ele tem que fazer atendimento só para aquilo não, mas tem que ter um atendimento aberto, a gente tem que entender que saúde a gente não tem distinção de orientação". (Coruja)

Nesse sentido, dentre as ações previstas tanto na política LGBT quanto nas três esferas de poder, propõese a educação permanente como estratégia de qualificar todos os atores sociais para sensibilizar sobre a temática (PEREIRA EO, 2015).

Nessa perspectiva, faz-se necessária a indispensável participação da Política Nacional de Humanização em todos os processos em saúde, para assim garantir o acesso igualitário e acolhimento às especificidades das demandas de saúde (PEREIRA EO, 2015; CARRARA S, 2012).

Dessa forma, a necessidade de formação profissional é um passo para ajudar a prevenir a discriminação e na construção de ações para especificidades da população LGBT (CARDOSO MR e FERRO LF, 2012). 
“...o profissional deve se despir dos preconceitos, das suas questões pessoais, de suas questões de crença e religião e de mitos e fantasias, é por isso que o profissional também deve ser analisado e tem que se despir de tudo de qualquer tipo de preconceito aí ele pode fazer um trabalho bom tanto com LBT ou não" (Abelha).

Existe essa potencialidade da educação em saúde, como uma ferramenta de transformação para um melhor atendimento a essa população. Para Laurentino ACN (2015), é preciso defender a educação permanente e continuada nos serviços, em todos os níveis de atenção da saúde, além da formação e capacitação de lideranças nos espaços sociais, gestores estaduais e municipais, e integrantes dos diversos conselhos. Isto é reverberado na concepção de Luz:

"Então, acho que na verdade, que acho que são a nossa bandeira principal que é: a educação dos profissionais, em forma de capacitação, de formação mesmo. Tendo em vista que esses profissionais saem das academias de profissionais de saúde sem é, ter noção do que é a população LGBT precisa, em relação a linha de cuidado né, é tanto que nem existe protocolos ainda pra esse cuidado. E aí, é a partir dessa conversa, dessa capacitação, sensibilização, formação a gente consegue fazer com os profissionais comecem a pensar nas suas práticas num direcionamento para população LGBT também" (Luz).

Os entrevistados apontam a Atenção Básica como porta de entrada preferencial do SUS, como ponto de partida para acolher de forma humanizada essa população, desde o acesso até o atendimento integral, superando práticas de saúde preconceituosas e discriminatórias (GUIMARÃES RCP, et al., 2017; LIONÇO T, 2008; CARRARA S, 2012).

"É ao mesmo tempo que a gente tem a dificuldade dos profissionais, a gente quando passa pelo processo de educação e sensibilização a gente descobre uma nova potência, que são de novo os profissionais. Então é yin-yang né, bem contra o mal parece a luta, existe um núcleo de resistência, existe um núcleo que quer fazer muito pela população. Então, uma potência é realmente as equipes de saúde da família, quando elas se sensibilizam para trabalhar com a população LGBT a gente consegue atingir a população LGBT dentro do território e fazendo o que o principal da saúde que é a promoção e prevenção da saúde né, então tem essa dualidade: a dificuldade na resistência né, de trabalhar o tema e tem a potencialidade de quando a equipe quer trabalhar a gente consegue fazer muita coisa pela população LGBT" (Luz).

Entretanto, essa sensibilização dos profissionais nos diversos níveis de complexidade da atenção, não constitui uma tarefa fácil, mas complexa, que pode comprometer o alcance do cumprimento das diretrizes das políticas (PEREIRA EO, 2015). Nas observações de Lionço T (2008) relaciona-se a prática preconceituosa de alguns profissionais à influência do padrão heteronormativo, e contribui para a construção de uma barreira no acesso dessa população aos serviços de saúde.

"A primeira é a resistência dos profissionais mesmo em trabalhar o tema né, por vários motivos: por falta de informação, por desconhecimento e também, principalmente né, por preconceito e discriminação relacionado ao tema, e aí, é a dificuldade maior. A outra é o entendimento muitas vezes, os profissionais têm que estamos criando núcleos de privilégios, quando a gente não está criando, a gente tá abrindo acesso para uma população que não tem acesso a saúde. Então hoje, a maior dificuldade que a gente tem de implementação é a metodologia de trabalho dos profissionais". (Luz)

É fundamental, portanto, superar essa resistência, pelos processos de formação, citadas por vários entrevistados, envolvendo diversas questões desde preconceito, sexualidade e atenção à saúde, acolhimento e tantas outras. Conforme Pereira EO (2015) é fundamental conhecer no primeiro momento, as diversas perspectivas do problema sob a ótica de diversos profissionais que atuam no sistema de saúde, para não 
trabalhar apenas a perspectiva cognitiva da informação e da norma, mas pelo ponto de vista da subjetividade de seus próprios preconceitos e valores. E como o direito de inclusão e cidadania da população LGBT na atenção à saúde.

\section{CONCLUSÃO}

Com esse estudo, espera-se expandir o conhecimento acerca da Atenção à Saúde Integral da População LGBT, como também contribuir na melhoria dos serviços direcionados a saúde dessa população, assim como o reconhecimento de que os gays, lésbicas, bissexuais, travestis e transexuais ainda não têm suas necessidades em saúde atendidas devido à discriminação e preconceitos baseados nas normas heteronormativas, e que essa mudança dependerá diretamente do modo de pensar e agir dos gestores e profissionais de saúde durante suas práticas em saúde. É fundamental que os gestores e profissionais de saúde reconheçam as particularidades da Atenção à Saúde da População LGBT, superando práticas de saúde preconceituosas e discriminatórias dos comportamentos sexuais divergentes do padrão heteronormatizado. Ademais, percebe-se a necessidade de aproximação dos profissionais com as políticas públicas, e as problemáticas específicas dessa população, com a finalidade de qualificar os serviços de saúde em seus diversos níveis de complexidade, cuidando para o atendimento igualitário e integral e combatendo as barreiras atitudinais que entravam o atendimento digno da população LGBT.

\section{REFERÊNCIAS}

1. ALBUQUERQUE GA, et al. Homossexualidade e o direito a saúde: um desafio para as políticas públicas de saúde no Brasil. Rio de Janeiro, Rio de Janeiro. Saúde Debate, 2013; 37 98: 516-524.

2. AYRES JRCM. Epidemiologia e emancipação. 2nd ed. São Paulo: Hucitec, 2005; 231p.

3. BARBOSA RM, FACCHINI R. Acesso a cuidados relativos à saúde sexual entre mulheres que fazem sexo com mulheres em São Paulo, Brasil. Caderno de Saúde Pública, 2009; 25 (sup 2): 291-300.

4. BRASIL. In: Secretária de Gestão Estratégica e Participativa. Política Nacional de Saúde Integral de Lésbicas, Gays, Bissexuais, Travestis e Transexuais. Institui, no âmbito do Sistema Único de Saúde, a Política Nacional de Saúde Integral de Lésbicas, Gays, Bissexuais, Travestis e Transexuais. Disponível em: http://bvsms.saude.gov.br/bvs/saudelegis/gm/2011/prt2836_01_12_2011.html. Acesso em: 18 de jan. 2018.

5. BRASIL. In: Instituto Brasileiro de Geografia e Estatística (IBGE). Diretoria de Pésquisas, Coordenação de População e Indicadores Sociais, Estimativas da população residente. Disponível em: https://cidades.ibge.gov.br/brasil/pe/recife. Acesso em 16 de set. 2017.

6. BOFF L. Saber cuidar: ética do humano - compaixão pela terra. 10nd ed. Petrópolis: Editora Vozes, 2004; 199p.

7. CARDOSO MR, FERRO LF. Saúde e População LGBT: Demandas e Especificidades em Questões. Revista de Psicologia: Ciência e Profissão. 2012; 32 (3): 552-563.

8. CARRARA S. Discriminação, políticas e direitos sexuais no Brasil. Cadernos de Saúde Pública, Rio de Janeiro. 2012; 28(1): 184-189.

9. CHIANCA, KSV. Implantação da Política Nacional da Atenção Integrada a Saúde do Homem: análise das possiblidades e limites. Dissertação (Mestrado em Enfermagem) - Universidade Federal da Paraíba. Joao Pessoa, 2011. $97 \mathrm{p}$.

10. FACCHINI R, BARBOSA RM. Dossiê Saúde das Mulheres Lésbicas: promoção da equidade e da integralidade. Rede Nacional Feminista de Saúde, Direitos Sexuais e Direitos Reprodutivos. Rede Feminista de Saúde. Belo Horizonte, 2006; 43 p.

11. GUIMARÃES RCP, et al. Assistência à saúde da população LGBT em uma capital brasileira: o que dizem os Agentes Comunitários de Saúde? Rev Tempus Actas de saúde coletiva, Brasília, 2017; 11(1): 121 -139.

12. LAURENTINO ACN. Políticas Públicas de saúde para a população LGBT: da criação do SUS à implementação da Política Nacional de Saúde Integral de LGBT. Dissertação (Mestrado em Educação Profissional em Saúde) - Escola Politécnica de Saúde Joaquim Venâncio, Fundação Oswaldo Cruz, Rio de Janeiro, 2015. 383 p.

13. LIONÇO T. Que direito à saúde para população GLBT? Considerando Humanos, Sexuais e Reprodutivos em Busca da Integralidade e da Equidade. Rev Saúde e Sociedade, 2008; 17(2):11-21.

14. MACEDO LC, et al. Análise do Discurso: uma reflexão para pesquisar em saúde. Comunicação Saúde Educação, 2008; $12(26): 649-657$.

15. Mello L, et al. Por onde andam as Políticas Públicas para a população LGBT no Brasil. Revista Sociedade e Estado, 2012; 27 (2): $289-312$.

16. MINAYO MCS. O desafio do conhecimento: pesquisa qualitativa em saúde. 2nd ed. São Paulo: Hucitec-Abrasco, 1993; $406 \mathrm{p}$.

17. ORLANDI PE. Análise de Discurso: princípios e procedimentos. 12nd ed. Campinas: Pontes Editores; $2015 ; 100$ p. 
18. RECIFE. Prefeitura Municipal do Recife. Plano Municipal de Saúde (2014-2017). 1nd ed. Recife: Secretária de Saúde do Recife; 2014; 84 p.

19. ROLIM AGF, et al. A realidade de um serviço de média complexidade, para o público LGBT, voltado para a atenção a saúde sexual e reprodutiva da população: do ideal ao real. Extramuros: Rev de Extensão da Universidade do Vale do São Francisco (UNIVASF). 2016; 4 (2): 138-146.

20. SOUZA MBCA, HELAL DH. Política nacional de saúde integral de lésbicas, gays, bissexuais, travestir e transexuais: análise descritiva e utilização de dados secundários para pesquisa e prática. Rev Bagoas, 2015; 13: 221 -251.

21. PAULA C EA, et al. Vulnerabilidade legislativa de grupos minoritários. Ciência \& Saúde Coletiva, $2017 ; 22$ (12): 3841 3848.

22. PEREIRA EO. Acesso e qualidade da atenção à saúde para a população LGBT: visão dos médicos de uma capital do nordeste brasileiro. Dissertação (Mestrado em Saúde Coletiva). Universidade de Brasília, Brasília, $2015 ; 77$ p.

23. PEREIRA EO, et al. Unidades básicas de saúde em Teresina- PI e o acesso da população LGBT: o que pensam os médicos. Rev Tempus Actas de Saúde Coletiva, 2017; 11 (1): 51-67.

24. PERNAMBUCO. Secretária Estadual de Saúde. Portaria $n^{\circ} 060$, de 10 de março de 2015. Instituir a Política Estadual de Saúde Integral de Lésbicas, Gays, Bissexuais, Travestis e Transexuais. Diário Oficial do Estado de Pernambuco. 2015.

25. PRADO EAJ, SOUSA MF. Políticas públicas e saúde da população LGBT: uma revisão integrativa. Brasília. Revista Tempus, actas de saúde coletiva, 2017; 11 (1): 69 -80.

26. VINUTO J. Amostragem em bola de neve na pesquisa qualitativa: um debate em aberto. Temáticas, Campinas, $2014 ; 22(44): 203-320$. 